\title{
Natural antioxidants isolated from Schinus areira leaves by ultrasound-assisted extraction
}

\author{
Liliana S. Celaya ${ }^{\mathrm{a}}$, Carmen I. Viturro ${ }^{\mathrm{a}}$, Luís R. Silva ${ }^{\mathrm{b}}$, And Silvia Moreno ${ }^{*}$ \\ ${ }^{\text {a }}$ PRONOA Laboratory, CIT JUJUY, UNJu-CONICET, Faculty of Engineering, University of Jujuy, Italo \\ Palanca, 10, 4600 San Salvador de Jujuy, Jujuy, Argentina \\ b CICS-UBI-Health Sciences Research Centre, University of Beira Interior, 6201-506 Covilhã, Portugal; \\ LEPABE-Department of Chemical Engineering, Faculty of Engineering, University of Porto, 4200-465 Porto, \\ Portugal; REQUIMTE- Pharmacognosy Laboratory, Department of Chemistry, Faculty of Pharmacy, \\ University of Porto, Rua de Jorge Viterbo Ferreira, 228, 4050-313 Porto, Portugal \\ ${ }^{\mathrm{c}}$ Leloir Institute Foundation, Plant Biochemistry Laboratory, IIBBA-Institute of Biochemical Research of \\ Buenos Aires, CONICET-National Scientific and Technical Research Council, Av. Patricias Argentinas 435, \\ 1405, Ciudad Autónoma de Buenos Aires, Argentina; Maimónides University, Ciudad Autónoma de Buenos \\ Aires, Hidalgo 775, 1405, Argentina \\ ${ }^{*}$ Corresponding author \\ smorenocontar@gmail.com \\ TEL: +54-11-5238-7500 \\ FAX: +54-11-5238-7501
}

Received: 17 September 2015; Published online: 18 October 2016

\begin{abstract}
The aim of this study was to optimize the extraction of antioxidant compounds from Schinus areira leaves using ultrasound assisted extraction and response surface methodology. The effect of sonication time and plant material:solvent ratio were used to optimize the recovery. Results showed that a high recovery of antioxidant compounds from leaves of three different $S$. areira specimens was achieved under optimized conditions. The leaf extracts obtained displayed a DPPH (1,1-Diphenyl-2-picrylhydrazyl) radical scavenging activity analogous to the well-known antioxidant trolox $\left(\mathrm{EC}_{50}=23-46\right.$ vs 36.1 $\mu \mathrm{g} / \mathrm{mL}$, respectively). In addition, these extracts showed a good potency to eliminate superoxide and nitric oxide-radicals as well as a moderate antimicrobial activity against gram positive Staphylococcus aureus and Enterococcus faecalis and yeast. HPLC chromatography analysis of the three S. areira leaf extracts showed different high contents of kaempferol-3-O-rutinoside, quercetin-3-O-galactoside and 3-O-caffeoylquinic acid. The results showed that the $S$. areira leaf extracts contained a high amount of antioxidant phenolic compounds, which might be a valuable source to be used as additives in plant-based foods.
\end{abstract}

Keywords: Schinus areira; Antioxidants; Free-radical scavenging; Ultrasound-assisted extraction; Antimicrobial activity

\section{Introduction}

Plant antioxidants are useful as food preservatives against oxidation reactions and microbial contamination, which are considered the major causes of food deterioration (Romano, Abadi,
Repetto, Vojnov, \& Moreno, 2009; Losasso et al., 2012; Martins, Arantes, Candeias, Tinoco, \& Cruz-Morais, 2014). Oxidative reactions also generate reactive oxygen species which are linked to carcinogenesis, inflammation, aging and cardiovascular disorders and many antiox- 
idant polyphenols exhibit beneficial effects on human health (Wan, Yuan, Cirello, \& Seeram, 2012; Barni, Carlini, Cafferata, Puricelli, \& Moreno, 2012; Mihaylova, Ivanova, Bahchevanska, \& Krastanov, 2015).

Since ancient times, spices and herbs have been added to different food for improve flavours and their antioxidant capacity (Petrovska, 2012). Plants synthesize antioxidant compounds, which are mainly phenolics, to counteract reactive oxygen species (ROS) that can cause oxidative damage. They do this through different mechanisms, such as free-radical scavenging, hydrogen donation, singlet oxygen quenching, and they act as a substrate for radicals such as superoxide and hydroxyl (Moreno, Scheyer, Romano, \& Vojnov, 2006; Zhao, Baik, Choi, \& Kim, 2014).

Ultrasound-assisted extraction is widely employed for the extraction of plant-derived antioxidants (Cortes-Rojas, Fernandes Souza, \& Oliveira, 2011; Daglia, 2012) because it is suitable to isolate thermolabile and unstable compounds and is an effective tool for optimizing the process when many factors and interactions affect desired response (Zhang, Wang, Zhang, Zhou, \& Guo, 2014; Mihaylova et al., 2015).

The Schinus genus, a member of the Anacardiaceae family, is a plant that is distributed widely in South America regions and is used in folk medicine as a digestive, a stimulant, a diuretic, an astringent, an antidepressant, as well as for topical use and in wound healing (Martinez \& Barboza, 2010). In Argentina, Schinus areira L. [synonymous: Schinus molle L. var. areira (L.) DC] grows naturally in pre-puna zone from an altitude of 1800 to $2300 \mathrm{~m}$ and in the Chaco-Serrano region (Viturro, Bandoni, Dellacassa, Serafini, \& Elder, 2010). A study of essential oil components of individualized specimens of $S$. areira tree was performed in six locations in the Northwest of Argentina, regions with the highest population density of this species, revealing different clusters based on their chemical profiles (Viturro et al., 2010).

Important effects of $S$. areira L. essential oils on airway inflammation and the cardiovascular system in mice and rabbits have been reported (Bigliani et al., 2012). This study also demonstrated that clinical status (morbidity or mortality), macroscopic morphology and lung/body weight index were unaffected by the administration of the oils.

We previously demonstrated that $S$. areira essential oils isolated from leaves and fruits have antibacterial activity (Celaya, Alabrudzinska, Molina, Viturro, \& Moreno, 2014). Essential oils of a related specie, Schinus molle, also exhibited antioxidant and antimicrobial properties (Martins et al., 2014).

In this study, we optimized the extraction of nonvolatile antioxidant compounds from $S$. areira leaves by ultrasound-assisted extraction, in order to determine the potential of these plants as sources of natural antioxidants. Furthermore, we reported the hydroxyl, nitric oxide and superoxide radical scavenging as well as the antibacterial activities of leaves optimized extracts from different $S$. areira specimens. The chemical composition of these leaf extracts was also determined.

\section{Materials and Methods}

\section{$2.1 \quad$ Materials}

S. areira leaves of different specimens: Tilcara g (Tg2), Tilcara c (Tce6) and Pinchayoc (Py1) were collected in May 2013 at different locations in Quebrada de Humahuaca (Jujuy province, Argentina). Voucher specimens were deposited in herbarium of PRONOA-UNJu (Faculty of Engineering from National University of Jujuy, Argentina). The harvested materials were air-dried at room temperature $\left(20{ }^{\circ} \mathrm{C}\right)$ for 1 week.

3-O-Caffeoylquinic acid, 5-O-caffeoylquinic acid, quercetin-3-O-galactoside, quercetin3-O-glucoside, quercetin-3-O-rutinoside, quercetin-3-O-arabinoside, quercetin-3-Orhamnoside, kaempferol-3-O-rutinoside standards were purchased from Extrasynthése (Genay, France). Gallic acid, 6-hydroxy-2,5,7,8tetramethylchroman-2-carboxylic acid (Trolox), $\beta$-nicotinamide adenine dinucleotide reduced form (NADH), phenazinemethosulfate (PMS), nitrotetrazolium blue chloride (NBT) and gentamicin were purchased from Sigma-Aldrich (St. Louis, MO, USA). 


\subsection{Ultrasound-assisted extraction}

S. areira leaves $(5 \mathrm{~g})$ were macerated in a 250 $\mathrm{mL}$ glass flask, and $100 \mathrm{~mL}$ of aqueous ethanol: $(30: 70 \%, v / v)$ was added. Aqueous ethanol solutions are suitable for extracting hydrophilic and lipophilic compounds by enabling the propagation of ultrasonic waves (Tabaraki, Heidarizadi, \& Benvidi, 2012). Ultrasound-assisted extraction was performed using an ultrasonic device (Cole-Parmer 8890 Instrument, USA) with a power of $80 \mathrm{~W}$ at a frequency of $47 \mathrm{kHz}$. It was equipped with a digital timer and run at room temperature. The water in the bath was replaced continuously to keep it close to room temperature. A 32 factorial experimental design was used for the extraction of antioxidant compounds. Twelve sets of experiments were performed using two independent variables: $\mathrm{X} 1=$ sonication time $(\mathrm{min})$ and $\mathrm{X} 2=$ solid to solvent ratio $(\mathrm{g} / 100 \mathrm{~mL})$ with coded levels $(-1,0,+1)$ : 15, 45, $75 \mathrm{~min}$ and $5,7.5$ and $10 \mathrm{~g} / 100 \mathrm{~mL}$, respectively. Extract concentration $(\mathrm{mg} / \mathrm{mL})$; yield (\%) extract/sample dry weight and DPPH radical scavenging activity $\left(\mathrm{EC}_{50}\right.$ value) were the three dependent variables employed. The $\mathrm{EC}_{50}$ value was determined as described in Item 2.3. After the extraction was finished, the extracts were filtered through Whatman No 1 filter paper. The extract was immediately assessed or kept in refrigerator in closed dark containers at $4{ }^{\circ} \mathrm{C}$ at a maximum time of 1 month. Values are expressed as mean \pm standard deviation from at least three assays, each performed in triplicate.

\subsection{Antioxidant activity}

The antioxidant activity was evaluated by the DPPH (1,1-diphenyl-2-picrylhydrazyl, SigmaAldrich, St. Louis, MO, USA) radical method. The ability of the $S$. areira leaf extracts to donate an electron and scavenge $\mathrm{DPPH}$ radical was determined by the method of Brand-Williams, Cuvelier, and Berset (1995). Briefly, a DPPH solution $(0.3 \mathrm{mM})$ was freshly prepared protected from light and $180 \mu \mathrm{L}$ of this solution were added to each well of 96-well flat-bottom microtitration plates (Greiner bio-one, GBO Argentina) containing samples of $15.6-1000.0 \mu \mathrm{g} / \mathrm{mL}$ leaf extracts. The absorbance of the samples was measured (Epoch microplate spectrophotometer, BIO TeK) and compared with the blank sample. Percentage inhibition after 30 min was plotted against concentration. The percentage inhibition of DPPH was determined according to the formula: $(\%)=\left[\left(\mathrm{A}_{0}-\mathrm{A}\right) / \mathrm{A}_{0}\right] \times 100$, where $\mathrm{A} 0$ and $\mathrm{A}$ are the absorbance values of the blank sample and the test, respectively. The antioxidant activity was expressed as the effective concentration $\left(\mathrm{EC}_{50}\right)$ value corresponding to the concentration of sample necessary to decrease the initial DPPH absorbance by $50 \%$ as described (Moreno et al., 2006).

The superoxide-radical $\left(\mathrm{O}_{2} \bullet-\right)$ scavenging assay and the nitric oxide-radical (NO•) scavenging assay were also performed. Serial dilutions of the initial S. areira leaf extracts (46- $3000.0 \mu \mathrm{g} / \mathrm{mL}$ ) were performed covering a wide range of concentrations by suspension in potassium phosphate buffer $\mathrm{pH}$ 7.0. $\mathrm{O}_{2} \bullet$ - induced reduction of NBT was performed by the generation of superoxide radicals with $\mathrm{NADH} / \mathrm{PMS}$ system and monitored at $560 \mathrm{~nm}$ during $2 \mathrm{~min}$ at room temperature, as described (Silva et al., 2014). The NO• scavenging activity was determined by the colorimetric assay using the Griess reagent and the chromophore formed was read at $562 \mathrm{~nm}$, as described in Oliveira et al. (2009). All experiments were performed in triplicate and at least repeated three times.

\subsection{Total phenolic content}

Total phenols were estimated according to the Folin-Ciocaulteau method (Tepe, Daferera, Sokmen, Sokmen, \& Polissiou, 2005). Plant extracts were diluted to the concentration of $1 \mathrm{mg} / \mathrm{mL}$, and aliquots of $0.5 \mathrm{~mL}$ were mixed with $2.5 \mathrm{~mL}$ of Folin-Ciocalteu reagent and $2 \mathrm{~mL}$ of $\mathrm{NaHCO}_{3}$ (7.5\%). After $15 \mathrm{~min}$ of staying at the $37{ }^{\circ} \mathrm{C}$ the absorbance was measured at $765 \mathrm{~nm}$ on spectrophotometer versus blank sample. Total phenols were determined as grams ( $\mathrm{g}$ ) of gallic acid equivalents (GAE) per $100 \mathrm{~g}$ of dry extract and the values presented were means of triplicate analyses. 


\subsection{Antibacterial activity}

Staphylococcus aureus American Type Culture Collection, ATCC 25922, Enterococcus faecalis ATCC 29212, Escherichia coli ATCC 35218 and yeast (Rhodotorula sp. and Candida albicans ATCC 90029) were used in this study. In order to reach stationary growth phase, bacteria were cultured at $37^{\circ} \mathrm{C}$ for $24 \mathrm{~h}$ in Mueller Hinton Broth (MH, Difco, MD, USA) and yeasts were cultured at $30^{\circ} \mathrm{C}$ in Sabouraud dextrose.

The antimicrobial activity was evaluated according to the agar diffusion method proposed by the Clinical and Laboratory Standard Institute (CLSI, 2006), but replacing the sterile paper discs by cylindrical cavities of $4 \mathrm{~mm}$ in diameter performed with a micropipette tip. As a positive control gentamicin $(400 \mu \mathrm{g})$ was used. Petri dishes were then incubated at $37{ }^{\circ} \mathrm{C}$ for $16-24 \mathrm{~h}$ and the halos of inhibition were measured using a caliper. All assays were performed at least in triplicate and data presented as mean \pm standard deviation.

A micro-dilution technique using 96-well microplates was used for quantitative evaluations (CLSI, 2006). Plant extracts $(50-800 \mu \mathrm{g} / \mathrm{mL})$ were assayed in 96-well plates with bacterial strain at a final density of $5 \times 105 \mathrm{CFU} / \mathrm{mL}$. The microplates were aseptically sealed and incubated at $37^{\circ} \mathrm{C}$ for $24 \mathrm{~h}$ under constant shaking $(100 \mathrm{rpm})$. Bacterial growth was determined by measuring the absorbance at $625 \mathrm{~nm}$ on a plate reader as described by Ojeda-Sana, van Baren, Elechosa, Juarez, and Moreno (2013). The minimal inhibitory concentration (MIC) was the lowest extract concentration at which bacterial growth was inhibited after $24 \mathrm{~h}$ incubation at $37^{\circ} \mathrm{C}$. The minimum bactericide concentration (MBC) was the lowest concentration of the plant extract that killed bacteria. All experiments were performed at least three times and in triplicate.

\subsection{Antibacterial activityChemical analysis by HPLC-DAD}

Separation of phenolics was performed with an analytical HPLC unit (Gilson). Twenty micro- liters ( 25 to $75 \mathrm{mg} / \mathrm{mL}$ ) of each extract dissolved in methanol, that had been previously filtered through a $0.45 \mu \mathrm{m}$ polytetrafluoroethylene membrane (Millipore, Bedford, MA), was applied on a using a Spherisorb ODS2 $(25.0 \mathrm{~cm} \times 0.46 \mathrm{~cm}$; $5 \mu \mathrm{m}$ particle size; Waters, Milford, MA) column, as described in Cabana, Silva, Valentao, Viturro, and Andrade (2013). The solvent system used was a gradient of water-formic acid (19:1) (A) and methanol (B): $0-5 \%$ B, 15\% B at $3 \mathrm{~min}, 25 \% \mathrm{~B}$ at $13 \mathrm{~min}, 30 \% \mathrm{~B}$ at $25 \mathrm{~min}$, $35 \% \mathrm{~B}$ at $35 \mathrm{~min}, 40 \% \mathrm{~B}$ at $39 \mathrm{~min}, 45 \% \mathrm{~B}$ at $42 \mathrm{~min}, 50 \% \mathrm{~B}$ at $44 \mathrm{~min}, 55 \% \mathrm{~B}$ at $47 \mathrm{~min}$, $70 \% \mathrm{~B}$ at $50 \mathrm{~min}, 75 \% \mathrm{~B}$ at $56 \mathrm{~min}$ and $80 \% \mathrm{~B}$ at $60 \mathrm{~min}$. The solvent flow rate used was 0.9 $\mathrm{mL} / \mathrm{min}$. Detection was achieved with a Gilson diode array detector (DAD), and chromatograms were recorded at 280, 320 and $350 \mathrm{~nm}$. The data were processed on Unipoint System software (Gilson Medical Electronics, Villiers le-Bel, France). The compounds in each sample were identified by comparing the retention times and UV-visible spectra in the range of $200-400 \mathrm{~nm}$ with those of authentic standards, or with the library of spectra previously collected. The quantification of phenolic compounds was achieved by the absorbance recorded in the chromatograms relative to external standards and performed in triplicate as described in Vinha et al. (2002). The limit values for phenolic compounds were between 0.04 and $4.30 \mu \mathrm{g} / \mathrm{mL}$ and the method was precise. 3-O-caffeoylquinic acid was quantified as 5-O-caffeoylquinic acid and quercetin derivatives as quercetin-3-O-glucoside, since standards were not commercially available. The other compounds were quantified as themselves. Phenolic compounds were expressed in $\mu \mathrm{g} / \mathrm{g}$ leaves extract and the relative percentage (\%) was calculated.

\section{7 $\quad$ Statistical analysis}

The experimental design was performed using Statgraphic Plus Software Version 5.1 (Manugistics, Rockville, MD, USA); a quadratic prediction was used for optimizing the antioxidant extraction. Significant effects (p-value $<0.05$ ) were defined using standardized Pareto chart for dropping coefficients without statistical significance. $\mathrm{EC}_{50}$ and $\mathrm{MIC}_{50}$ values were calculated by ap- 
plying logarithmic regression analysis from the mean inhibitory values with Graphpad Prism 5 Software (San Diego, CA, USA). All data were tested for significance using the one way analysis of variance (ANOVA) with the post-hoc Tukey HSD test; differences were considered significant when $\mathrm{p}<0.05$. Results were expressed as means \pm standard deviation of at least three independent experiments.

\section{Results and Discussion}

\subsection{Extraction of antioxidant compounds from $S$. areira leaves by ultrasound-assisted extraction}

Table 1 shows the $3^{2}$ factorial experimental designs using as dependent variables: the DPPH radical scavenging activity extract concentration, extract yield and as function of sonication time and solid to solvent ratio (X1 and X2) with 4 replicates of the centre point applied to recover antioxidant compounds from $S$. areira leaves. Leaves from Tg2 $S$. areira specimen were selected, since it is a well characterized specimen from the $\beta$-phellandrene chemotype of essential oil fruits (Viturro et al., 2010). Parameters for linear and quadratic effects and their interactions were analyzed and statistical significance of the variable responses were performed by standardized Pareto chart and fitness of the prediction inspected by the coefficient $\mathrm{R}^{2}$ at $95 \%$ confidence level (for $\mathrm{p}$-value $<0.05$ ). Results of variance analysis for response surface of leaves extract concentration, yield and DPPH radicalscavenging activity showed $\mathrm{R}^{2}$ values of 79.4 , 77.6 and 73.5 , respectively.

Following this, the 3D response surface model was used to evaluate the interaction of the independent variables to define the optimum level of each variable evaluated. Response surface optimization is more advantageous than the traditional single parameter optimization since it saves time, space and raw material. In Fig. 1 , the predicted results show that an increment in the sonication time improved the leaf extract concentrations and yields (Fig. 1A and
B). On the other hand, the antioxidant activity was highest at the minor sonication time and dropped to a minimum between 30-40 min of sonication time, probably by induction of oxidative conversion of antioxidant compounds on longer extraction times (Figure 1C).

Data for the predicted and experimental values of the dependent variables analyzed are shown in Table 2. The predicted value for the recovery of the highest antiradical activity of leaf extracts $\left(\mathrm{EC}_{50}=22.2 \mu \mathrm{g} / \mathrm{mL}\right)$ using a sonication time of $15 \mathrm{~min}$ and a solid to solvent ratio of $5 \mathrm{~g} / 100 \mathrm{~mL}$ matched with the experimental value obtained previously $\left(\mathrm{EC}_{50}=23.3 \mu \mathrm{g} / \mathrm{mL}\right.$, see Table 1$)$.

The same experimental design was applied to obtain antioxidants from fruits, but 10 times less antioxidant activity was found in fruit extracts. Therefore, our findings confirmed good significance for the response of variables chosen to extract antioxidant compounds from $S$. areira leaves obtaining ethanolic leaf extracts with a high free-radical scavenging activity close to the activity of the well-known antioxidant Trolox $\left(\mathrm{EC}_{50}\right.$ value of $\left.36.1 \pm 0.3 \mu \mathrm{g} / \mathrm{mL}\right)$.

\subsection{Recovery of antioxidant compounds from leaves of different $S$. areira specimens}

It is important to investigate whether the optimal conditions described above to extract antioxidant can be applied to other specimens of $S$. areira. To perform this study other two $S$. areira typical specimens (Tce6 and Py1) growing at different locations in the Jujuy Province were chosen. Table 3 shows that although the antioxidant activity using the DPPH assay of both leaf extracts was slightly lower compared to $\mathrm{Tg} 2$, they were comparable to that of Trolox. More thorough investigation of the antioxidant activity of the three optimized extracts obtained by means of their free radical scavenging effect on superoxide $\left(\mathrm{O}_{2} \bullet-\right)$ and nitric oxide $(\mathrm{NO} \bullet)$ radicals Showed that all leaf extracts had a great antiradical capability against the $\mathrm{O}_{2} \bullet$ - radical, though in this occasion the Tce6 leaf extract showed the most activity (Table 3). All extracts exhibited a free radical scavenging effect on nitric oxide radicals analogous to that of the ascor- 

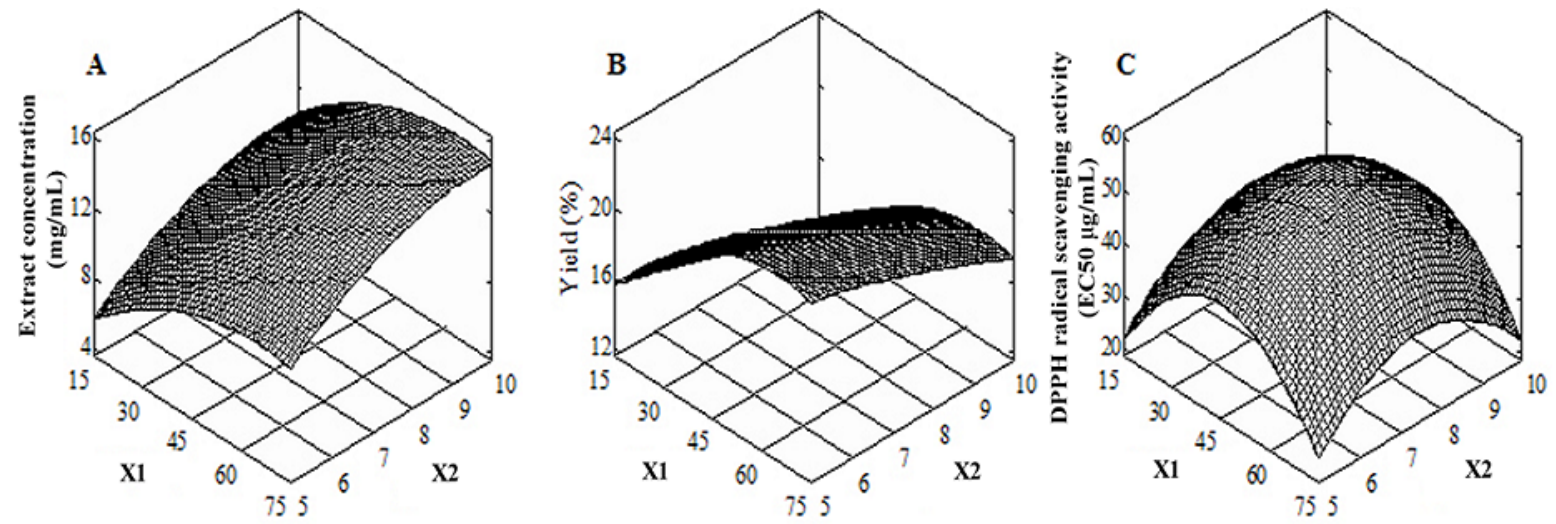

Figure 1: Response surface plots showing the effect of sonication time (X1) and solid to solvent ratio (X2) on the extract concentration (A), yield (B) and DPPH radical scavenging activity (C) of S. areira leaf extracts.

Table 1: Experimental design for recovery of antioxidant compounds from Tg2 S. areira leaves

\begin{tabular}{lccccc}
\hline \multirow{2}{*}{ Experiments } & \multicolumn{2}{c}{ Coded levels } & Responses & $\mathrm{D}$ \\
\cline { 2 - 5 } & $\mathrm{X}^{a}$ & $\mathrm{X}^{b}$ & $\begin{array}{c}\text { Extract concentration } \\
(\mathrm{mg} / \mathrm{mL})\end{array}$ & $\begin{array}{c}\text { Yield } \\
(\%)\end{array}$ & $\begin{array}{c}\text { DPPH radical scavenging } \\
\text { activity }\left(\mathrm{EC}_{50}, \mu g / m L\right)\end{array}$ \\
\hline 1 & $-1(15)$ & $-1(5.0)$ & $7.0 \pm 0.7$ & $16.0 \pm 1.7$ & $23.3 \pm 1.1$ \\
2 & $0(45)$ & $-1(5.0)$ & $8.4 \pm 0.8$ & $18.9 \pm 1.7$ & $30.6 \pm 0.1$ \\
3 & $1(75)$ & $-1(5.0)$ & $10.1 \pm 0.1$ & $22.3 \pm 0.1$ & $26.6 \pm 0.7$ \\
4 & $-1(15)$ & $0(7.5)$ & $9.6 \pm 1.1$ & $14.5 \pm 1.7$ & $25.8 \pm 0.7$ \\
5 & $0(45)$ & $0(7.5)$ & $12.0 \pm 1.2$ & $17.9 \pm 1.8$ & $62.7 \pm 0.8$ \\
6 & $0(45)$ & $0(7.5)$ & $14.0 \pm 1.6$ & $20.9 \pm 2.4$ & $60.2 \pm 1.3$ \\
7 & $0(45)$ & $0(7.5)$ & $13.6 \pm 2.1$ & $20.4 \pm 3.1$ & $58.1 \pm 2.0$ \\
8 & $0(45)$ & $0(7.5)$ & $12.8 \pm 1.7$ & $19.2 \pm 2.5$ & $57.9 \pm 2.1$ \\
9 & $1(75)$ & $0(7.5)$ & $14.4 \pm 0.6$ & $21.2 \pm 0.9$ & $24.3 \pm 0.5$ \\
10 & $-1(15)$ & $1(10.0)$ & $9.1 \pm 0.9$ & $10.2 \pm 1.0$ & $28.3 \pm 0.3$ \\
11 & $0(45)$ & $1(10.0)$ & $16.2 \pm 2.1$ & $18.2 \pm 2.4$ & $29.5 \pm 0.3$ \\
12 & $1(75)$ & $1(10.0)$ & $14.4 \pm 1.2$ & $15.9 \pm 1.3$ & $25.2 \pm 0.3$ \\
Trolox & - & - & - & - & $36.1 \pm 0.5$ \\
\hline
\end{tabular}

${ }^{a} \mathrm{X} 1=$ sonication time $(\mathrm{min})$

${ }^{b} \mathrm{X} 2=$ plant material to solvent ratio $(\mathrm{g} / 100 \mathrm{~mL})$ 
Table 2: Predicted and experimental values of dependent variables for the extraction of antioxidants from Tg2 S. areira leaves

\begin{tabular}{|c|c|c|c|c|}
\hline \multirow[t]{2}{*}{ Response } & \multicolumn{2}{|c|}{ Optimized conditions } & \multirow{2}{*}{$\begin{array}{l}\text { Predicted } \\
\text { value }\end{array}$} & \multirow{2}{*}{$\begin{array}{c}\text { Experimenta } \\
\text { value }\end{array}$} \\
\hline & $\mathrm{X} 1^{a}$ & $\mathrm{X} 2^{b}$ & & \\
\hline Extract concentration $(\mathrm{mg} / \mathrm{mL})$ & 70.0 & 10.0 & 15.5 & $13.1 \pm 0.8$ \\
\hline Yield $(\%)$ & 67.2 & 5.6 & 21.7 & $18.7 \pm 1.7$ \\
\hline DPPH radical scavenging activity $\left(\mathrm{EC}_{50}, \mu \mathrm{g} / \mathrm{mL}\right)$ & 15.0 & 5.0 & 22.2 & $23.3 \pm 1.1$ \\
\hline
\end{tabular}

${ }^{a} \mathrm{X} 1=$ sonication time $(\min )$

${ }^{b} \mathrm{X} 2=$ plant material to solvent ratio $(\mathrm{g} / 100 \mathrm{~mL})$

bic acid value $\left(\mathrm{EC}_{50}=400 \mu \mathrm{g} / \mathrm{mL}\right)$ reported by Singh et al. (2012).

As a result, the optimized $S$. areira leaf extracts obtained in this work exhibited the ability to eliminate labile $\mathrm{H}$ atoms, superoxide and nitric oxide-radicals, which are ubiquitous physiological free radicals implicated in many human diseases as cancer, neurodegeneration and other pathological inflammation conditions (Sen, Chakraborty, Sridhar, Reddy, \& De, 2010).

Table 3 also shows the phenolic content of the three leaf extracts analyzed by the FolinCiocaulteau method. An equivalent amount of phenolic in Tg2 and Tce6 leaves extract specimens ( $p>0.05)$, was found, while Py1 had a significantly lower amount (Table 3 ). Thus, the high content of antioxidant phenolic compounds in the leaf extracts may have been the responsible for the radical scavenging-activity observed.

\subsection{Antimicrobial activity of $S$. areira leaf extracts}

The antimicrobial activity of the three leaf extracts was evaluated by the disk diffusion technique towards bacteria and yeasts (Table 4). Moderate activity against the Gram-positive $S$. aureus and E. faecalis bacteria was observed, while no activity against the Gram-negative bacteria $E$. coli was observed up to the maximum concentration tested $(1600 \mu \mathrm{g} / \mathrm{mL})$. Antiyeast activity against Candida albicans and Rhodotorula sp. was also found (Table 4).

The antibacterial activity assessed by the microdilution technique against $S$. aureus, and E. fae- calis showed a dose-dependent inhibition activity for all the leaf extracts assessed (Figure 2). Both Tg2 and Tce6 leaf extracts totally inhibited the bacterial growth at $400 \mu \mathrm{g} / \mathrm{mL}$ (MICs values), while bactericide activity was found using $2 \mathrm{x}$ MIC of Tg2 and Tce 6 after $24 \mathrm{~h}$ of incubation against $S$. aureus. Lower antimicrobial activity for Py1 leaf extract was observed.

The bactericidal activity of essential oils isolated from fruits and leaves of $\mathrm{Tg} 2$ and $\mathrm{Py} 1$ S. areira specimens against susceptible and methicillin resistant $S$. aureus strains was previously reported by us (Celaya et al., 2014). Data from this work indicated that the ethanolic leaf extract of those specimens, as well as the Tce6 S. areira plant studied here, also exhibited antibacterial and anti-yeast activity.

All findings showed that both antimicrobial and antioxidant activities co-exist in the same extract for the three $S$. areira specimens analyzed. Accordingly, antioxidant activity and anti-yeast activity in methanol extracts of Schinus molle growing in northeast Mexico was also found (Salazar-Aranda, Alejandro Perez-Lopez, LopezArroyo, Alicia Alanis-Garza, \& Waksman de Torres, 2011).

\subsection{HPLC analysis of $S$. areira leaf extracts}

The main peaks identified in the Tg2 $S$. areira specimen by HPLC analysis were quercetin-3O-galactoside and 3-O-caffeoylquinic acid (compound 8 and 2, respectively; Figure 3), while kaempferol-3-O-rutinoside was the predominant constituent in Tce6 and Py1 extracts (compound 
Table 3: Free radical scavenging activity and total phenolic content of Tg2, Tce6 and Py1 S. areira optimized leaves extracts

\begin{tabular}{lccc}
\hline Assays $^{a}$ & \multicolumn{1}{c}{ Tg2 } & Tce6 & Py1 \\
\hline \multirow{3}{*}{$\mathrm{DPPH}^{\bullet}$} & $23.3 \pm 1.1^{*}$ & $39.4 \pm 0.4^{* *}$ & $43.9 \pm 0.6^{* * *}$ \\
\cline { 2 - 4 } $2^{\bullet--}$ & $60.6 \pm 2.0^{* * *}$ & $38.5 \pm 1.0^{*}$ & $53.9 \pm 1.1^{* *}$ \\
$\mathrm{NO}^{\bullet} b$ & $457.6 \pm .12 .1^{*}$ & $442.0 \pm 15.3^{*}$ & $483.0 \pm 42.3^{*}$ \\
Total phenolics & $g \mathrm{GAE} / 100 \mathrm{~g}$ dry extract & \\
\cline { 2 - 4 } & $29 \pm 1.04^{*}$ & $29 \pm 0.93^{*}$ & $18 \pm 0.75^{* *}$
\end{tabular}

$\overline{{ }^{a}}$ The same sign in the line indicates no statistical difference (Tukey's HSD test, p > 0.05)

${ }^{b}$ Singh et al. (2012) reported an $E C_{50}=400 \mu \mathrm{g} / \mathrm{mL}$ for the ascorbic acid

Table 4: Antimicrobial activity of Tg2, Tce6 and Py1 S. areira leaves extracts by the agar diffusion method

\begin{tabular}{lccccc}
\hline Samples & \multicolumn{4}{c}{ Inhibition halos $(\mathrm{mm})^{a}$} \\
\cline { 2 - 6 } & Bacteria & S. aureus & E. faecalis & E. coli & Yeast \\
& $8.9 \pm 0.7^{*}$ & $6.2 \pm 0.2^{*}$ & n.a. $^{b}$ & $8.6 \pm 0.7^{*}$ & $6.0 \pm 0.1^{*}$ \\
\hline Tg2 $(400 \mu \mathrm{g})$ & $9.1 \pm 0.8^{*}$ & $6.3 \pm 0.2^{*}$ & n.a. & $7.6 \pm 0.8^{*}$ & $6.1 \pm 0.3^{*}$ \\
Tce6 $(400 \mu \mathrm{g})$ & $7.5 \pm 0.5^{* *}$ & $5.9 \pm 0.1^{*}$ & n.a. & $8.2 \pm 0.6^{*}$ & $5.9 \pm 0.1^{*}$ \\
Py1 $(400 \mu \mathrm{g})$ & $32.5 \pm 1.7^{* * *}$ & $21.2 \pm 0.7^{* *}$ & $20 \pm 0.8$ & n.t. & n.t. \\
Gentamicin $(400 \mu \mathrm{g})$ & n.t. & n.t. & n.t. & $24.0 \pm 0.2$ & $10.4 \pm 0.4$ \\
Potassium sorbate $(400 \mu \mathrm{g})$ & & &
\end{tabular}

${ }^{a}$ The same sign in the column indicates no statistical difference ( $\mathrm{p}>0.05$ Tukey's HSD test)

${ }^{b}$ Not active

${ }^{c}$ Not tested

Table 5: Quantification of phenolic compounds in Tg2, Tce6 and Py1 S. areira leaf extracts $(\mu g / g$ dry extracts)

\begin{tabular}{|c|c|c|c|}
\hline Compounds $^{a, b}$ & $\operatorname{Tg} 2$ & Tce6 & Py1 \\
\hline Phenolic acid derivative 1 & $1108.1 \pm 3.6(2.7 \%)$ & $4609.6 \pm 70.8(6.4 \%)$ & $1252.5 \pm 2.0(1.9 \%)$ \\
\hline 3-O-caffeoylquinic acid & $8523.0 \pm 39.5(\mathbf{2 1 \%})$ & $5704.2 \pm 7.3(7.9 \%)$ & $13074.4 \pm 14.8(\mathbf{1 9 . 8 \%})$ \\
\hline 5-O-caffeoylquinic acid & $461.3 \pm 0.4(1.1 \%)$ & $256.2 \pm 0.5(0.4 \%)$ & $990.7 \pm 3.4(1.5 \%)$ \\
\hline Quercetin derivative 1 & $3168.2 \pm 7.7(7.8 \%)$ & $4153.7 \pm 8.1(5.8 \%)$ & $1956.8 \pm 14.2(3.0 \%)$ \\
\hline Quercetin derivative 2 & $721.3 \pm 6.1(1.78 \%)$ & n.q $q^{d}$ & $629.6 \pm 0.4(1.0 \%)$ \\
\hline Phenolic acid derivative 2 & $594.8 \pm 3.3(1.5 \%)$ & $330.8 \pm 2.4(0.5 \%)$ & $2799.8 \pm 0.7(4.2 \%)$ \\
\hline Quercetin derivative 3 & $574.0 \pm 15.0(1.4 \%)$ & $4698.4 \pm 34.5(6.5 \%)$ & $4361.9 \pm 1.1(6.6 \%)$ \\
\hline Quercetin-3- $O$-galactoside & $18764.1 \pm 29.5(\mathbf{4 6 . 2 \%})$ & $8775.5 \pm 21.2(12.2 \%)$ & $7105.6 \pm 48.3(10.8 \%)$ \\
\hline Quercetin-3- $O$-glucoside & $1042.7 \pm 8.1(2.6 \%)$ & n.q. & $1461.3 \pm 5.0(2.2 \%)$ \\
\hline Quercetin derivative 4 & $1100.2 \pm 7.8(2.7 \%)$ & $25.5 \pm 0.1(0.1 \%)$ & $494.6 \pm 6.0(0.8 \%)$ \\
\hline Quercetin-3- $O$-arabinoside & $1413.4 \pm 1.7(3.5 \%)$ & $35.33 \pm 0.2(0.1 \%)$ & $263.6 \pm 2.1(0.4 \%)$ \\
\hline Quercetin-3- $O$-rhamnoside & $1995.5 \pm 17.8(4.9 \%)$ & $84.3 \pm 2.4(0.1 \%)$ & $533.4 \pm 1.1(0.8 \%)$ \\
\hline Kaempferol 3-O-rutinoside & $1129.9 \pm 2.3(2.8 \%)$ & $43220.8 \pm 69.2(\mathbf{6 0 . 1 5})$ & $31162.3 \pm 1.1(\mathbf{4 7 . 2 \%})$ \\
\hline$\sum c$ & 40596.5 & 71894.3 & 66086.5 \\
\hline
\end{tabular}

${ }^{a}$ Values are expressed as mean \pm standard deviation of three assays

${ }^{b}$ Relative percentage of compounds in brackets

${ }^{c}$ Relative percentage of compol phenolic compounds

${ }^{c}$ Total phenolic
${ }^{d}$ Non quantified 


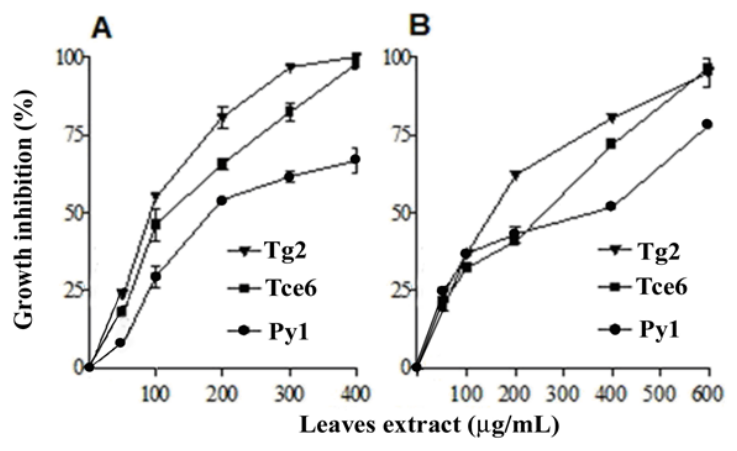

Figure 2: Antibacterial activity of $S$. areira leaf extracts against $S$. aureus (A) and E. faecalis (B) by the microdilution assay.

13; Figure 3). Table 5 shows the quantification of these main constituents in the $S$. areira leaf extracts. Results showed that three chemical profiles in the $S$. areira leaf extracts can be recognized: Tg2 extract rich in quercetin3-O-galactoside (46.2\%) with 3-O-caffeoylquinic acid $(21.0 \%)$, Py1 extract rich in kaempferol-3O-rutinoside (47\%) with 3-O-caffeoylquinic acid $(19.8 \%)$ and Tce6 extract rich in kaempferol-3O-rutinoside $(60.1 \%)$. Other minor components were quercetin and phenolic acid derivatives. We do not know yet whether the differences in chemical composition of the three leaves extracts are due to different plant growth conditions or because they are genetically determined.

Taking into the account the results presented herein, it could inferred that the effectiveness of $S$. areira leaf extracts as antioxidant and antibacterial agents depend on an adequate range and concentration of bioactive compounds. Accordingly, the high antioxidant activity exhibited by Tg2 leaf extracts against DPPH radical may possibly be associated with its high content of quercetin-3-O-galactoside and 3-O-caffeoylquinic acid. Quercetin, one of the flavonoids found widely in the human diet, has been reported to have many health benefits and it is a promising agent for the prevention of systemic inflammatory diseases such as sepsis (Chang, Tsai, Sheu, Hsieh, \& Chiang, 2013). In addition, the antioxidant properties of hydroxycinammic acid derivatives, like 3-O-caffeoylquinic acid, are well- known (Marzouk, Moharram, Haggag, Ibrahim, \& Badary, 2006; Ibrahim \& Haggag, 2013; Teixeira \& Silva, 2013). On the other hand, the best antiradical scavenger against $\mathrm{O}_{2} \bullet-$ and $\mathrm{NO} \bullet$ exhibited by the TCe6 leaf extracts could be associated with the highest amount of kaempferol3-O-rutinoside. Both quercetin and kaempferol have been found to protect cerebellar cells from oxidative damage and apoptosis by scavenging hydroxyl radicals and kaempferol exhibit strong alkylperoxyl radical scavenging activity in vitro (Chen et al., 1999; Shahidi \& Naczk, 2003). We cannot discount some type of synergism between the active compounds and/or with minor components of the leaf extracts.

\section{Conclusions}

In the search for natural alternatives to synthetic additives used for food preservation, we reported here suitable experimental conditions using ultrasound-assisted extraction to obtain leaf extracts of different $S$. areira specimens exhibiting a high antioxidant activity. Importantly, our results have demonstrated for the first time, the ability of the $S$. areira leaf extracts to eliminate superoxide and nitric oxide-radicals, which are ubiquitous physiological free radicals implicated in many human diseases. From a practical point of view, our results indicate that the $S$. areira leaf extracts containing a high amount of flavonols and hydroxycinnamic acids may be an interesting source of antioxidant compounds for food applications in plant-based products.

\section{Acknowledgements}

This research was supported by ANPCyT (Grant PICTO UNJu 00150), European Union FEDER funds: COMPETE and frame work of QREN (Project NORTE-07-0124-FEDER000069), Fundação para a Ciência e Tecnologia (project Pest-C/EQB/LA0006/2013) and CONICET, Argentina (Grant PIP 00894). The authors would like to thank Prof. M.E. Schmalkos (Univ. of Misiones, Argentina) for his help with the statistical analysis. Celaya L.S. is indebted to the scholarship Erasmus Mundus programme EUROTANGO II Argentina. Moreno S. is mem- 
$176 \mid$ Celaya et al.
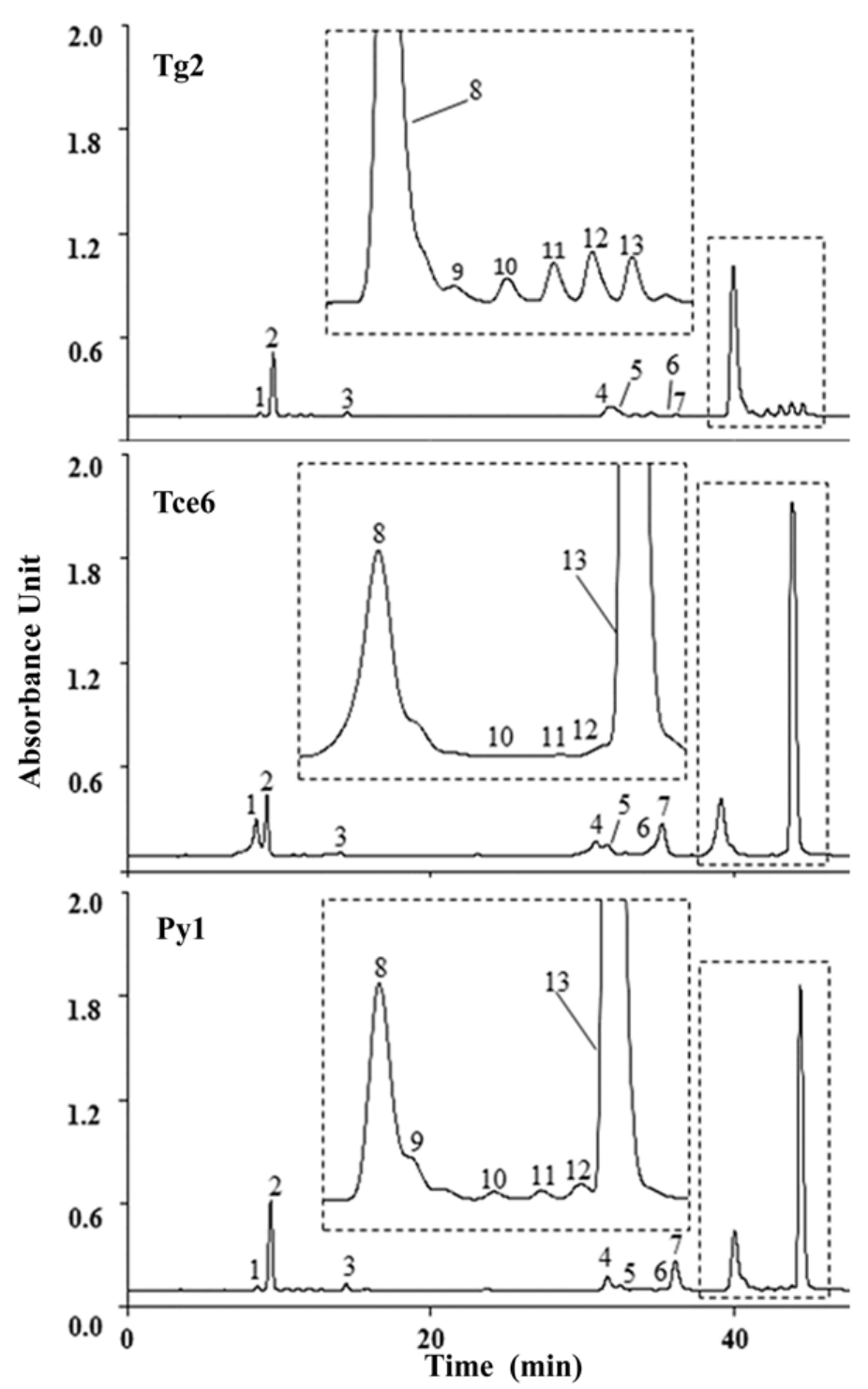
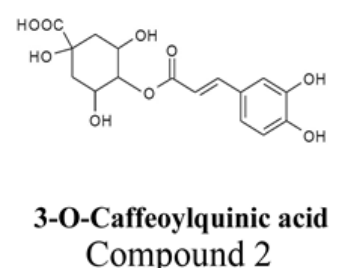

3-O-Caffeoylquinic acid Compound 2
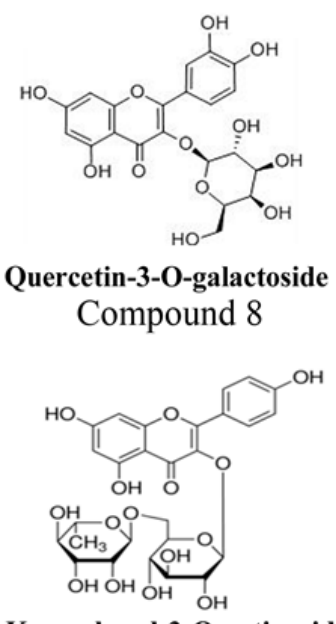

Kaempherol-3-O-rutinoside Compound 13

Figure 3: Characteristic chromatogram of S. areira extracts after HPLC analysis on the left. Numbers corresponding to: phenolic acid derivative (1); 3-O-caffeoylquinic acid (2); 5-O-caffeoylquinic acid (3); quercetin derivative 1 and 2 (4 and 5); phenolic acid derivative 2 (6); quercetin derivative 3 (7); quercetin-3-O-galactoside (8); quercetin-3-O-glucoside (9); quercetin derivative (10); quercetin-3-Oarabinoside (11); quercetin 3-O-rhamnoside (12); kaempferol 3-O-rutinoside (13). Molecular structures of 3-O-caffeoylquinic acid (compound 2), quercetin-3-O-galactoside (compound 8) and kaempferol-3-Orutinoside (compound 13) on the right. 
ber of the Research Scientific Career from CONICET. Luís R. Silva is grateful to Foundation for Science and Technology (FCT) by the post doc grant (SFRH/BPD/105263/2014)

\section{References}

Barni, M. V., Carlini, M. J., Cafferata, E. G., Puricelli, L., \& Moreno, S. (2012). Carnosic acid inhibits the proliferation and migration capacity of human colorectal cancer cells. Oncology Reports, 27(4), 1041-1048. doi:10.3892/or.2012.1630

Bigliani, M. C., Rossetti, V., Grondona, E., Lo Presti, S., Paglini, P. M., Rivero, V., ... Ponce, A. A. (2012). Chemical compositions and properties of Schinus areira L. essential oil on airway inflammation and cardiovascular system of mice and rabbits. Food and Chemical Toxicology, 50(7), 2282-2288. doi:10.1016/j.fct.2012.04.025

Brand-Williams, W., Cuvelier, M. E., \& Berset, C. (1995). Use of a free-radical method to evaluate antioxidant activity. Food Science and Technology-lebensmittelwissenschaft \& Technologie, 28(1), 25-30.

Cabana, R., Silva, L. R., Valentao, P., Viturro, C. I., \& Andrade, P. B. (2013). Effect of different extraction methodologies on the recovery of bioactive metabolites from Satureja parvifolia (Phil.) Epling (Lamiaceae). Industrial Crops and Products, 48, 49-56. doi:10.1016/j.indcrop.2013.04.003

Celaya, L. S., Alabrudzinska, M. H., Molina, A. C., Viturro, C. I., \& Moreno, S. (2014). The inhibition of methicillinresistant Staphylococcus aureus by essential oils isolated from leaves and fruits of Schinus areira depending on their chemical compositions. Acta Biochimica Polonica, 61(1), 41-46. 5th Central European Congress of Life Sciences (EUROBIOTECH), Krakow, POLAND, 2013.

Chang, Y.-C., Tsai, M.-H., Sheu, W. H.-H., Hsieh, S.-C., \& Chiang, A.-N. (2013). The Therapeutic Potential and Mechanisms of Action of Quercetin in Relation to Lipopolysaccharide-Induced Sepsis In
Vitro and In Vivo. Plos One, 8(11). doi:10. 1371/journal.pone.0080744

Chen, C., Wei, T. T., Gao, Z. H., Zhao, B. L., Hou, J. W., Xu, H. B., ... Packer, L. (1999). Different effects of the constituents of EGb761 on apoptosis in rat cerebellar granule cells induced by hydroxyl radicals. Biochemistry and Molecular Biology International, 47(3), 397-405.

CLSI. (2006). Methods for dilution antimicrobial susceptibility test for bacteria that grow aerobically; approved standard (7 ed., approved standard M7-A7 ed). Wayne, PA.

Cortes-Rojas, D. F., Fernandes Souza, C. R., \& Oliveira, W. P. (2011). Optimisation of the extraction of phenolic compounds and antioxidant activity from aerial parts of Bidens pilosa L. using response surface methodology. International Journal of Food Science and Technology, 46(11), 2420-2427. doi:10.1111/j.1365-2621.2011. 02765.x

Daglia, M. (2012). Polyphenols as antimicrobial agents. Current Opinion in Biotechnology, 23(2), 174-181. doi:10.1016/j.copbio.2011. 08.007

Ibrahim, M. T. \& Haggag, E. G. (2013). Phenolics from Schinus molle stems and their anti-bacterial and anti-microalgal activity. Life Science Journal, 10, 1931-1937.

Losasso, C., Cibin, V., Cappa, V., Roccato, A., Vanzo, A., Andrighetto, I., \& Ricci, A. (2012). Food safety and nutrition: Improving consumer behaviour. Food Control, 26 (2), 252-258. doi:10.1016/j. foodcont . 2012.01.038

Martinez, G. J. \& Barboza, G. E. (2010). Natural pharmacopoeia used in traditional Toba medicine for the treatment of parasitosis and skin disorders (Central Chaco, Argentina). Journal of Ethnopharmacology, 132(1), 86-100. doi:10.1016/j.jep. 2010. 07.049

Martins, M. d. R., Arantes, S., Candeias, F., Tinoco, M. T., \& Cruz-Morais, J. (2014). Antioxidant, antimicrobial and toxicological properties of Schinus molle L. essential oils. Journal of Ethnopharmacology, 151(1), 485-492. doi:10.1016/j.jep.2013. 10.063 
Marzouk, M. S., Moharram, F. A., Haggag, E. G., Ibrahim, M. T., \& Badary, O. A. (2006). Antioxidant flavonol glycosides from Schinus molle. Phytotherapy Research, 20(3), 200-205. doi:10.1002/ptr . 1834

Mihaylova, D., Ivanova, M., Bahchevanska, S., \& Krastanov, A. (2015). Chemical composition and antioxidant activity of ultrasound-assisted extract of the endemic plant Haberlea rhodopensis Friv. Journal of Food Science and Technology-mysore, 52(4), 2469-2473. doi:10.1007/s13197-0131240-3

Moreno, S., Scheyer, T., Romano, C. S., \& Vojnov, A. A. (2006). Antioxidant and antimicrobial activities of rosemary extracts linked to their polyphenol composition. Free Radical Research, 40(2), 223231. doi:10.1080/10715760500473834

Ojeda-Sana, A. M., van Baren, C. M., Elechosa, M. A., Juarez, M. A., \& Moreno, S. (2013). New insights into antibacterial and antioxidant activities of rosemary essential oils and their main components. Food Control, 31(1), 189-195. doi:10.1016/j foodcont . 2012.09.022

Oliveira, A. P., Valentao, P., Pereira, J. A., Silva, B. M., Tavares, F., \& Andrade, P. B. (2009). Ficus carica L.: Metabolic and biological screening. Food and Chemical Toxicology, 47(11), 2841-2846. doi:10.1016/j. fct.2009.09.004

Petrovska, B. (2012). Historical review of medicinal plants' usage. Pharmacognosy Reviews, 6(11), 1-5. doi:10.4103/0973-7847.95849. eprint: http://www.phcogrev.com/article. asp issn $=0973-7847$; year $=2012 ;$ volume $=$ $6 ;$ issue $=11 ;$ spage $=1 ;$ epage $=5 ;$ aulast $=$ Petrovska; $\mathrm{t}=6$

Romano, C. S., Abadi, K., Repetto, V., Vojnov, A. A., \& Moreno, S. (2009). Synergistic antioxidant and antibacterial activity of rosemary plus butylated derivatives. Food Chemistry, 115(2), 456-461. doi:10. 1016/j.foodchem.2008.12.029

Salazar-Aranda, R., Alejandro Perez-Lopez, L., Lopez-Arroyo, J., Alicia Alanis-Garza, B., \& Waksman de Torres, N. (2011). Antimicrobial and Antioxidant Activities of Plants from Northeast of Mexico. Evidence-based Complementary and Alternative Medicine, 1-6. doi:10.1093/ecam/ nep 127

Sen, S., Chakraborty, R., Sridhar, C., Reddy, Y. S. R., \& De, B. (2010). Free radicals, antioxidants, diseases and phytomedicines: current status and future prospect. International Journal of Pharmaceutical Sciences Review and Research, 3(1), 91-100.

Shahidi, F. \& Naczk, M. (2003). Phenolics in food and nutraceuticals. CRC press.

Silva, L. R., Azevedo, J., Pereira, M. J., Carro, L., Velazquez, E., Peix, A., ... Andradet, P. B. (2014). Inoculation of the Nonlegume Capsicum annuum (L.) with Rhizobium Strains. 1. Effect on Bioactive Compounds, Antioxidant Activity, and Fruit Ripeness. Journal of Agricultural and Food Chemistry, 62(3), 557-564. doi:10.1021/ jf4046649

Singh, D., Mishra, M., Gupta, M., Singh, P., Gupta, A., \& Nema, R. (2012). Nitric Oxide radical scavenging assay of bioactive compounds present in methanol Extract of Centellaasiatica. International Journal of Pharmacy and Pharmaceutical Science Research, 2(3), 42-4.

Tabaraki, R., Heidarizadi, E., \& Benvidi, A. (2012). Optimization of ultrasonic-assisted extraction of pomegranate (Punica granatum L.) peel antioxidants by response surface methodology. Separation and Purification Technology, 98, 16-23. doi:10.1016/j. seppur.2012.06.038

Teixeira, R. \& Silva, L. R. (2013). Bioactive compounds and in vitro biological activity of Euphrasia rostkoviana Hayne extracts. Industrial Crops and Products, 50, 680-689. doi:10.1016/j.indcrop.2013.08.035

Tepe, B., Daferera, D., Sokmen, A., Sokmen, M., \& Polissiou, M. (2005). Antimicrobial and antioxidant activities of the essential oil and various extracts of Salvia tomentosa Miller (Lamiaceae). Food Chemistry, 90(3), 333-340. doi:10.1016/j.foodchem. 2003.09.013

Vinha, A. F., Silva, B. M., Andrade, P. B., Seabra, R. M., Pereira, J. A., \& Oliveira, M. (2002). Development and evaluation of 
an HPLC/DAD method for the analysis of phenolic compounds from olive fruits. Journal of Liquid Chromatography \& Related Technologies, 25(1), 151-160. doi:10. 1081/JLC-100108546

Viturro, C., Bandoni, A., Dellacassa, E., Serafini, L., \& Elder, H. (2010). Normalización de productos naturales obtenidos de especies de la flora aromática latinoamericana. In DellaCassa, Eduardo (Org.) (Ed.), (Chap. 10: Problemática Schinus en Latinoamérica, pp. 205-280). Proyecto CYTED IV.20, Porto Alegre: Edit. Universitária da PUCRS.

Wan, C., Yuan, T., Cirello, A. L., \& Seeram, N. P. (2012). Antioxidant and alphaglucosidase inhibitory phenolics isolated from highbush blueberry flowers. Food Chemistry, 135(3), 1929-1937. doi:10 . 1016/j.foodchem.2012.06.056

Zhang, Y. B., Wang, L. H., Zhang, D. Y., Zhou, L. L., \& Guo, Y. X. (2014). Ultrasound-assisted extraction and purification of schisandrin B from Schisandra chinensis (Turcz.) Baill seeds: Optimization by response surface methodology. Ultrasonics Sonochemistry, 21(2), 461-466. doi:10.1016/j.ultsonch.2013.09.009

Zhao, S., Baik, O.-D., Choi, Y. J., \& Kim, S.-M. (2014). Pretreatments for the Efficient Extraction of Bioactive Compounds from Plant-Based Biomaterials. Critical Reviews in Food Science and Nutrition, 54(10), 1283-1297. doi:10.1080/10408398. 2011.632698 